\title{
Dilute Solution Properties of Randomly Branched Poly(methyl methacrylate). I.
}

\author{
Kensuke Kamada and Hiroshi Sato \\ Central Research Laboratory, Mitsubishi Rayon Company, Ltd., \\ Otake, Hiroshima, Japan.
}

(Received February 5, 1971)

\begin{abstract}
The intrinsic viscosity and the sedimentation constant of randomly branched polydisperse polymers were calculated using a molecular-weight distribution function derived by Stockmayer and incorporating this function into the theories of intrinsic viscosity and friction constant of a branched molecule. Randomly branched polydisperse polymers were prepared by copolymerization of methyl methacrylate with ethylene dimethacrylate and the hydrodynamic properties were determined by experiment and compared with the theories. It was found that the intrinsic viscosity of randomly branched polymers was well characterized by Zimm and Kilb's g $^{1 / 2}$-rule, at least in the theta state.
\end{abstract}

KEY WORDS Branch / Poly(methyl methacrylate)/ Molecular Weight

Distribution / Intrinsic Viscosity / Sedimentation / Dilute Solution /

Dilute solution properties of branched polymers have been studied both experimentally and theoretically by many investigators. Especially in recent years, characteristic samples such as the star-type molecule have become available, due to anionic polymerization techniques, and detailed experimental studies have been carried out for clarifying the effect of branching on the average chain dimension, intrinsic viscosity and so on. ${ }^{1,2}$ Thus in the case of a star molecule, it is now well established that the intrinsic viscosity $[\eta]_{b}$ obeys the prediction of Zimm and Kilb's theory, ${ }^{3}$ i.e.,

$$
[\eta]_{b}=[\eta]_{1} \cdot g^{1 / 2}
$$

where $[\eta]_{1}$ is the intrinsic viscosity of a linear molecule having the same molecular weight as the star molecule. The notation $g$ represents the well-known "contraction factor" which is defined in terms of the mean square radii of gyration, $\left\langle S^{2}\right\rangle_{\mathrm{b}}$ and $\left\langle S^{2}\right\rangle_{1}$, by

$$
\left\langle S^{2}\right\rangle_{b}=g\left\langle S^{2}\right\rangle_{1}
$$

In these equations, all quantities stand for the values measured in the theta state.

On the other hand, in the case of randomly branched molecules it is rather difficult to assess the effect of branching separately from the effect of molecular weight distribution. As was pointed out by $\mathrm{Kilb}^{4}$, the $z$-average value of $\left\langle S^{2}\right\rangle$ of an unfractionated sample, for example, becomes quite insensitive to the average degree of branching as a result of mutual cancellation between the effects of branching and molecular weight distribution. It is also uncertain whether the intrinsic viscosity obeys eq 1 or not.

To clarify the effects of branching on the dilute solution properties of randomly branched molecules, therefore, it seems essential to prepare a sample with a suitably characteristic distribution of molecular weight and to carry out experiments carefully on it, preferably in theta solvents. This series of papers represents the results of experiments performed along these lines. In part I, a series of model branched polymers is prepared by copolymerization of methyl methacrylate(MMA) with ethylene dimethacrylate(EDMA) and the hydrodynamic properties, intrinsic viscosity, and sedimentation constant, of unfractionated polydisperse samples are investigated. This combination of monomers is known to give an ideal model sample of randomly branched polymers, for vinyl bonds in these two monomers are equal in reactivity.

In part II, the hydrodynamic properties and the radius of gyration of fractionated samples 
of this polymer will be studied both in theta and good solvents.

\section{THEORETICAL}

\section{Calculation of Intrinsic Viscosity of Randomly Branched Polymers}

A calculation of intrinsic viscosity of randomly branched polydisperse polymers has been presented by Kilb. ${ }^{4}$ We here repeat this calculation not only with the exponent of $g$ factor in eq 1 equal to $1 / 2$ but also 1 and $3 / 2$ in order to make a detailed comparison with experimental results.

According to the theory of Stockmayer ${ }^{5,6}$, the weight fraction of $(l, n)$ mer, $W_{n, l}$ which contains $l$ bi-functional monomers and $n$ tetra-functional monomers is given approximately as

$$
\begin{aligned}
& W_{0, l}=\left(2 X / Y_{w}\right) \exp \{-X(1+\gamma / 2)\} \\
& W_{n, l}=\left[\gamma X^{3} / 2 n(2 n+1)(2 n+2)\right] W_{n-1, l}
\end{aligned}
$$

where $X=2 l / Y_{w}$ is the relative degree of polymerization (DP), $Y_{w}$ is the weight-average DP of the primary molecules and $r$ is a parameter often termed the branching parameter. $\gamma$ is equal to $\rho Y_{w}$, where $\rho$ is the fraction of double bonds contained in divinyl molecules(EDMA) which form cross-linking. The weight fraction $W_{x}$ of molecules having a relative degree of polymerization $X$ and the average number of branch units in a molecule are then calculated by eq 5 and 6 .

$$
\begin{aligned}
& W_{x}=\left(Y_{w} / 2\right) \sum_{n} W_{n, x} \\
& n_{x}=\sum_{n} n W_{n, x} / \sum_{n} W_{n, x}
\end{aligned}
$$

Following Stockmayer, we can put

$$
\begin{aligned}
X_{w} & =Y_{w} /(1-\gamma) \\
X_{n} & =Y_{n} /(1-\gamma / 4)
\end{aligned}
$$

where $X_{w}, X_{n}$ and $Y_{w}, Y_{n}$ are the weight-average and the number-average degrees of polymerization of the branched and primary molecules respectively. The weight-average number of branch units (or cross-links) per molecule in the whole polymer can be shown as

$$
n_{w}=\sum_{x} n_{x} W_{x} / \sum_{x} W_{x}=\gamma /(1-\gamma)
$$

We express the intrinsic viscosity of a monodisperse linear polymer as

$$
[\eta]_{1}=K k^{a}
$$

where $k$ is the DP of the linear polymer, $K$ and $a$ are constants. The intrinsic viscosity of a monodisperse branched polymer having the same degree of polymerization $k$ may be written in the form:

$$
[\eta]_{b}=B(g)[\eta]_{\mathrm{I}}
$$

where $B(g)$ is a function of $g$. The average value of the intrinsic viscosity of polydisperse branched molecules is then given by

$$
\left\langle[\eta]_{\mathrm{b}}\right\rangle=K \sum_{k} \sum_{n} B(g) k^{a} W_{n, k}
$$

The weight-average value of $B(g)$ per molecule having degree of polymerization $k\left(=Y_{w} X / 2\right)$ is given by

$$
\langle B(g)\rangle=\sum_{n} B(g) W_{n, x} / \sum_{n} W_{n, x}
$$

Inserting eq 5 and 13 in eq 12 and replacing summation by integration results in

$$
\begin{gathered}
\left\langle[\eta]_{\mathrm{b}}\right\rangle=K\left(Y_{w} / 2\right)^{a} f(\gamma, a) \\
f(\gamma, a)=\int_{0}^{\infty} X^{a}\langle B(g)\rangle W_{x} d x
\end{gathered}
$$

The average intrinsic viscosity of the corresponding linear molecules having the same weightaverage degree of polymerization as the branched molecules is obtained from eq 8 and 14 .

$$
\left\langle[\eta]_{1}\right\rangle=K\left[Y_{w} / 2(1-\gamma)\right]^{a} f(0, a)
$$

Consequently:

$$
\left\langle[\eta]_{\mathrm{b}} /\left\langle[\eta]_{1}\right\rangle=(1-\gamma)^{a} f(\gamma, a) / f(0, a)\right.
$$

According to Zimm and Stockmayer ${ }^{7}$, the $g$ value of a randomly branched polymer is not highly sensitive to the form of the distribution of the branch unit and is given by

$$
\langle g(n)\rangle=\left[(1+n / 6)^{1 / 2}+4 n / 3 \pi\right]^{-1 / 2}
$$

Thus the average value of $g$ about molecules having degree of polymerization $k$ is approximately

$$
\begin{aligned}
\langle g\rangle= & \sum_{n} g(n) W_{n, x} / \sum_{n} W_{n, x} \\
& \cong\left[\left(1+n_{x} / 6\right)^{1 / 2}+4 n_{x} / 3 \pi\right]^{-1 / 2}
\end{aligned}
$$

Moreover, in order to simplify the calculation, $\langle B(g)\rangle$ is assumed to be equal to $B(\langle g\rangle)$. 
Dilute Solution Properties of Branched PMMA. I

Table I. Theoretical values $\left\langle[\eta]_{b}\right\rangle /\left\langle[\eta]_{1}\right\rangle$ as functions of $\gamma$, and $B(g)$

\begin{tabular}{|c|c|c|c|c|c|c|c|}
\hline \multirow{3}{*}{$\gamma$} & \multicolumn{6}{|c|}{$\left\langle[\eta]_{\mathrm{b}}\right\rangle \mid\left\langle[\eta]_{\mathrm{l}}\right\rangle$} & \\
\hline & \multicolumn{3}{|c|}{$a=0.5$} & \multirow{2}{*}{$\frac{a=0.6}{g^{1 / 2}}$} & \multicolumn{3}{|c|}{$a=0.7$} \\
\hline & $g^{1 / 2}$ & $g$ & $g^{3 / 2}$ & & $g^{1 / 2}$ & $g$ & $g^{3 / 2}$ \\
\hline 0 & 1.000 & 1.000 & 1.000 & 1.000 & 1.000 & 1.000 & 1.000 \\
\hline 0.10 & 0.969 & 0.951 & 0.934 & 0.967 & 0.967 & 0.945 & 0.925 \\
\hline 0.20 & $0.936(0.94)^{\mathrm{a}}$ & 0.901 & 0.870 & 0.933 & 0.932 & 0.891 & 0.854 \\
\hline 0.30 & 0.900 & 0.849 & 0.805 & 0.895 & 0.893 & 0.833 & 0.782 \\
\hline 0.40 & $0.858(0.87)^{\mathrm{a}}$ & 0.792 & 0.737 & 0.852 & 0.849 & 0.770 & 0.706 \\
\hline 0.50 & 0.811 & 0.729 & 0.665 & 0.802 & 0.799 & 0.701 & 0.626 \\
\hline 0.60 & $0.754(0.79)^{\mathrm{a}}$ & 0.658 & 0.587 & 0.740 & 0.738 & 0.623 & 0.539 \\
\hline 0.70 & 0.685 & 0.576 & 0.500 & 0.670 & 0.664 & 0.533 & 0.444 \\
\hline 0.80 & $0.593(0.61)^{\mathrm{a}}$ & 0.476 & 0.400 & 0.575 & 0.567 & 0.425 & 0.337 \\
\hline 0.90 & $0.458(0.47)^{\mathrm{a}}$ & 0.341 & 0.276 & 0.434 & 0.424 & 0.283 & 0.209 \\
\hline 0.92 & 0.419 & 0.307 & 0.245 & 0.394 & 0.383 & 0.247 & 0.180 \\
\hline 0.94 & 0.372 & 0.266 & 0.210 & 0.346 & 0.313 & 0.192 & 0.137 \\
\hline 0.96 & 0.317 & 0.218 & 0.170 & 0.292 & 0.283 & 0.161 & 0.111 \\
\hline
\end{tabular}

a ( ), Kilb's value.

Table II. Results of calculation of $W_{x}, n_{x},\left\langle h^{-1}(n)\right\rangle$, and $h^{-1}\left(n_{x}\right)$ in the case of $\gamma=0.50$

\begin{tabular}{|c|c|c|c|c|}
\hline$X$ & $W_{x}$ & $n_{x}$ & $\left\langle h^{-1}(n)\right\rangle$ & $h^{-1}\left(n_{x}\right)$ \\
\hline 0.000 & $0.000 \mathrm{E}(+00)$ & - & - & - \\
\hline 0.125 & $1.069 \mathrm{E}(-01)$ & $4.069 \mathrm{E}(-05)$ & $1.083 \mathrm{E}(+00)$ & $1.083 \mathrm{E}(+00)$ \\
\hline 0.250 & $1.830 \mathrm{E}(-01)$ & $3.255 \mathrm{E}(-04)$ & $1.083 \mathrm{E}(+00)$ & $1.083 \mathrm{E}(+00)$ \\
\hline 0.375 & $2.349 \mathrm{E}(-01)$ & $1.098 \mathrm{E}(-03)$ & $1.083 \mathrm{E}(+00)$ & $1.083 \mathrm{E}(+00)$ \\
\hline 0.500 & $2.683 \mathrm{E}(-01)$ & $2.600 \mathrm{E}(-03)$ & $1.083 \mathrm{E}(+00)$ & $1.082 \mathrm{E}(+00)$ \\
\hline 0.625 & $2.876 \mathrm{E}(-01)$ & $5.071 \mathrm{E}(-03)$ & $1.083 \mathrm{E}(+00)$ & $1.082 \mathrm{E}(+00)$ \\
\hline 0.750 & $2.963 \mathrm{E}(-01)$ & $8.743 \mathrm{E}(-03)$ & $1.083 \mathrm{E}(+00)$ & $1.082 \mathrm{E}(+00)$ \\
\hline 0.875 & $2.972 \mathrm{E}(-01)$ & $1.384 \mathrm{E}(-02)$ & $1.083 \mathrm{E}(+00)$ & $1.081 \mathrm{E}(+00)$ \\
\hline 1.000 & $2.925 \mathrm{E}(-01)$ & $2.058 \mathrm{E}(-02)$ & $1.083 \mathrm{E}(+00)$ & $1.080 \mathrm{E}(+00)$ \\
\hline 2.000 & $1.925 \mathrm{E}(-01)$ & $1.518 \mathrm{E}(-01)$ & $1.084 \mathrm{E}(+00)$ & $1.072 \mathrm{E}(+00)$ \\
\hline 3.000 & $1.149 \mathrm{E}(-01)$ & $4.280 \mathrm{E}(-01)$ & $1.087 \mathrm{E}(+00)$ & $1.072 \mathrm{E}(+00)$ \\
\hline 4.000 & $7.342 \mathrm{E}(-02)$ & $7.900 \mathrm{E}(-01)$ & $1.094 \mathrm{E}(+00)$ & $1.083 \mathrm{E}(+00)$ \\
\hline 5.000 & $5.054 \mathrm{E}(-02)$ & $1.178 \mathrm{E}(+00)$ & $1.104 \mathrm{E}(+00)$ & $1.098 \mathrm{E}(+00)$ \\
\hline 6.000 & $3.672 \mathrm{E}(-02)$ & $1.570 \mathrm{E}(+00)$ & $1.116 \mathrm{E}(+00)$ & $1.113 \mathrm{E}(+00)$ \\
\hline 7.000 & $2.772 \mathrm{E}(-02)$ & $1.964 \mathrm{E}(+00)$ & $1.129 \mathrm{E}(+00)$ & $1.129 \mathrm{E}(+00)$ \\
\hline 8.000 & $2.153 \mathrm{E}(-02)$ & $2.358 \mathrm{E}(+00)$ & $1.143 \mathrm{E}(+00)$ & $1.144 \mathrm{E}(+00)$ \\
\hline 9.000 & $1.709 \mathrm{E}(-02)$ & $2.753 \mathrm{E}(+00)$ & $1.157 \mathrm{E}(+00)$ & $1.159 \mathrm{E}(+00)$ \\
\hline 10.000 & $1.381 \mathrm{E}(-02)$ & $3.148 \mathrm{E}(+00)$ & $1.170 \mathrm{E}(+00)$ & $1.173 \mathrm{E}(+00)$ \\
\hline 11.000 & $1.132 \mathrm{E}(-02)$ & $3.543 \mathrm{E}(+00)$ & $1.184 \mathrm{E}(+00)$ & $1.186 \mathrm{E}(+00)$ \\
\hline 12.000 & $9.387 \mathrm{E}(-03)$ & $3.939 \mathrm{E}(+00)$ & $1.196 \mathrm{E}(+00)$ & $1.199 \mathrm{E}(+00)$ \\
\hline 13.000 & $7.863 \mathrm{E}(-03)$ & $4.335 \mathrm{E}(+00)$ & $1.209 \mathrm{E}(+00)$ & $1.211 \mathrm{E}(+00)$ \\
\hline 14.000 & $6.643 \mathrm{E}(-03)$ & $4.731 \mathrm{E}(+00)$ & $1.220 \mathrm{E}(+\infty 0)$ & $1.223 \mathrm{E}(+00)$ \\
\hline 21.000 & $2.406 \mathrm{E}(-03)$ & $7.506 \mathrm{E}(+00)$ & $1.293 \mathrm{E}(+00)$ & $1.295 \mathrm{E}(+00)$ \\
\hline 28.000 & $1.035 \mathrm{E}(-03)$ & $1.028 \mathrm{E}(+01)$ & $1.352 \mathrm{E}(+00)$ & $1.354 \mathrm{E}(+00)$ \\
\hline 56.000 & $6.972 \mathrm{E}(-05)$ & $2.139 \mathrm{E}(+01)$ & $1.524 \mathrm{E}(+00)$ & $1.523 \mathrm{E}(+00)$ \\
\hline 84.000 & $7.199 \mathrm{E}(-06)$ & $3.250 \mathrm{E}(+01)$ & $1.644 \mathrm{E}(+00)$ & $1.646 \mathrm{E}(+00)$ \\
\hline
\end{tabular}


Table III. Results of calculation of $W_{x}, n_{x},\left\langle h^{-1}(n)\right\rangle$, and $h^{-1}\left(n_{x}\right)$ in the case of $\gamma=0.90$.

\begin{tabular}{ccccc}
\hline$X$ & $W_{x}$ & $n_{x}$ & $\left\langle h^{-1}(\boldsymbol{n})\right\rangle$ & $h^{-1}\left(\boldsymbol{n}_{x}\right)$ \\
\hline 0.000 & $0.000 \mathrm{E}(+00)$ & - & - & - \\
0.125 & $1.043 \mathrm{E}(-01)$ & $7.324 \mathrm{E}(-05)$ & $1.083 \mathrm{E}(+00)$ & $1.083 \mathrm{E}(+00)$ \\
0.250 & $1.741 \mathrm{E}(-01)$ & $5.857 \mathrm{E}(-04)$ & $1.083 \mathrm{E}(+00)$ & $1.083 \mathrm{E}(+00)$ \\
0.375 & $2.181 \mathrm{E}(-01)$ & $1.975 \mathrm{E}(-03)$ & $1.083 \mathrm{E}(+00)$ & $1.082 \mathrm{E}(+00)$ \\
0.500 & $2.433 \mathrm{E}(-01)$ & $4.674 \mathrm{E}(-03)$ & $1.083 \mathrm{E}(+00)$ & $1.082 \mathrm{E}(+00)$ \\
0.625 & $2.548 \mathrm{E}(-01)$ & $9.105 \mathrm{E}(-03)$ & $1.083 \mathrm{E}(+00)$ & $1.082 \mathrm{E}(+00)$ \\
0.750 & $2.568 \mathrm{E}(-01)$ & $1.567 \mathrm{E}(-02)$ & $1.083 \mathrm{E}(+00)$ & $1.081 \mathrm{E}(+00)$ \\
0.875 & $2.522 \mathrm{E}(-01)$ & $2.475 \mathrm{E}(-02)$ & $1.083 \mathrm{E}(+00)$ & $1.080 \mathrm{E}(+00)$ \\
1.000 & $2.434 \mathrm{E}(-01)$ & $3.668 \mathrm{E}(-02)$ & $1.083 \mathrm{E}(+00)$ & $1.079 \mathrm{E}(+00)$ \\
2.000 & $1.451 \mathrm{E}(-01)$ & $2.557 \mathrm{E}(-01)$ & $1.085 \mathrm{E}(+00)$ & $1.070 \mathrm{E}(+00)$ \\
3.000 & $8.646 \mathrm{E}(-02)$ & $6.579 \mathrm{E}(-01)$ & $1.091 \mathrm{E}(+00)$ & $1.078 \mathrm{E}(+00)$ \\
4.000 & $5.772 \mathrm{E}(-02)$ & $1.125 \mathrm{E}(+00)$ & $1.102 \mathrm{E}(+00)$ & $1.095 \mathrm{E}(+00)$ \\
5.000 & $4.191 \mathrm{E}(-02)$ & $1.602 \mathrm{E}(+00)$ & $1.117 \mathrm{E}(+00)$ & $1.115 \mathrm{E}(+00)$ \\
6.000 & $3.218 \mathrm{E}(-02)$ & $2.081 \mathrm{E}(+00)$ & $1.133 \mathrm{E}(+00)$ & $1.134 \mathrm{E}(+00)$ \\
7.000 & $2.569 \mathrm{E}(-02)$ & $2.561 \mathrm{E}(+00)$ & $1.150 \mathrm{E}(+00)$ & $1.152 \mathrm{E}(+00)$ \\
8.000 & $2.111 \mathrm{E}(-02)$ & $3.042 \mathrm{E}(+00)$ & $1.167 \mathrm{E}(+00)$ & $1.169 \mathrm{E}(+00)$ \\
9.000 & $1.773 \mathrm{E}(-02)$ & $3.523 \mathrm{E}(+00)$ & $1.183 \mathrm{E}(+00)$ & $1.185 \mathrm{E}(+00)$ \\
10.000 & $1.517 \mathrm{E}(-02)$ & $4.004 \mathrm{E}(+00)$ & $1.198 \mathrm{E}(+00)$ & $1.201 \mathrm{E}(+00)$ \\
11.000 & $1.316 \mathrm{E}(-02)$ & $4.486 \mathrm{E}(+00)$ & $1.213 \mathrm{E}(+00)$ & $1.216 \mathrm{E}(+00)$ \\
12.000 & $1.156 \mathrm{E}(-02)$ & $4.968 \mathrm{E}(+00)$ & $1.227 \mathrm{E}(+00)$ & $1.230 \mathrm{E}(+00)$ \\
13.000 & $1.025 \mathrm{E}(-02)$ & $5.450 \mathrm{E}(+00)$ & $1.241 \mathrm{E}(+00)$ & $1.243 \mathrm{E}(+00)$ \\
14.000 & $9.171 \mathrm{E}(-03)$ & $5.932 \mathrm{E}(+00)$ & $1.254 \mathrm{E}(+00)$ & $1.256 \mathrm{E}(+00)$ \\
21.000 & $4.966 \mathrm{E}(-03)$ & $9.309 \mathrm{E}(+00)$ & $1.332 \mathrm{E}(+00)$ & $1.334 \mathrm{E}(+00)$ \\
28.000 & $3.197 \mathrm{E}(-03)$ & $1.269 \mathrm{E}(+01)$ & $1.396 \mathrm{E}(+00)$ & $1.398 \mathrm{E}(+00)$ \\
51.000 & $1.082 \mathrm{E}(-03)$ & $2.620 \mathrm{E}(+01)$ & $1.580 \mathrm{E}(+00)$ & $1.581 \mathrm{E}(+00)$ \\
84.000 & $5.613 \mathrm{E}(-04)$ & $3.972 \mathrm{E}(+01)$ & $1.709 \mathrm{E}(+00)$ & $1.710 \mathrm{E}(+00)$ \\
& & & & \\
& & & &
\end{tabular}

The calculation was performed with the following three types of function $B(g)$ : (i) ZimmKilb type, $B(g)=g^{1 / 2}$, (ii) Stockmayer-Fixman ${ }^{8}$ type; $B(g)=g$, (iii) Flory-Fox type; $B(g)=g^{3 / 2}{ }^{2}$ In the calculation of eq 15 , Kilb's method was used; that is, in the range $X=0$ to $X=84$ the integration was carried out by Simpson's rule, and in the range of $X$ higher than $84, W_{x}$ was replaced by a proper Gaussian function and the integral was reduced to the incomplete gamma function evaluated from Pearson's tables ${ }^{9}$. The integration by Simpson's rule was performed on a high-speed N1AC 2202 computer.

$f(\gamma, a)$ was calculated for various $\gamma$ and $a$ values. These results are given in Table $I$ in the form of eq 14 . In this table the values calculated by Kilb are also shown in brackets. These values are a little higher than ours. The reason for this discrepancy is not clear. As expected, the ratio of intrinsic viscosity of a branched molecule to that of a linear one monotonously decreases as the branching parameter $\gamma$ increases. The ratio also decreases as the exponent of $g$ in $B(g)$ increases.

In Tables II and III, values of $W_{x}$ and $n_{x}$ are given with $\gamma=0.50$ and 0.90 as examples.

Calculation of Sedimentation Constant of Polydisperse Branched Polymers.

According to the theory of Kurata and Fukatsu $^{10}$, in the limit of nondraining, the sedimentation constant of a branched molecule $S_{\mathrm{b}}$ is given by

$$
S_{\mathrm{b}}=h^{-1} S_{1}
$$

where $S_{1}$ is the sedimentation constant of a linear molecule and $h$ is the ratio of the Stokes radius of the branched molecule to that of the linear molecule of the same molecular weight. In the case of tetra-functional branching, $h^{-1}$ can be asymptotically given as

$$
\begin{aligned}
h^{-1} \simeq & \frac{1}{2} \Gamma(7 / 4)(3 n+1)^{1 / 4} \\
& +(11 / 16) \Gamma(5 / 4)(3 n+1)^{-1 / 4}
\end{aligned}
$$

for large $n . \quad \Gamma$ is the gamma function. 


\section{Dilute Solution Properties of Branched PMMA. I}

Now it is known for a monodisperse linear polymer that:

$$
S_{1}=K^{\prime} k^{\nu}
$$

where $K^{\prime}$ and $\nu$ are constants. Using the same method as for the calculation of intrinsic viscosity, therefore, we can obtain the weight-average sedimentation constant of polydisperse randomly branched polymers, i.e.,

$$
\left\langle S_{\mathrm{b}}\right\rangle=K^{\prime}\left(Y_{w} / 2\right)^{\nu} \int_{0}^{\infty} X^{\nu}\left\langle h_{x}^{-1}(n)\right\rangle W_{x} \mathrm{~d} x
$$

where $\left\langle h_{x}^{-1}(n)\right\rangle$ is written as

$$
\left\langle h_{x}^{-1}(n)\right\rangle=\sum_{n=0}^{\infty} h^{-1}(n) \dot{W_{n, x}} / \sum_{n=0}^{\infty} W_{n, x}
$$

Thus the ratio of the average sedimentation constant of branched molecules to that of linear molecules having the same weight-average degree of polymerization is given by

$$
\left\langle S_{\mathrm{b}}\right\rangle \mid\left\langle S_{1}\right\rangle=(1-\gamma)^{\nu} S(\gamma, \nu) / S(0, \nu)
$$

where

$$
S(\gamma, \nu)=\int_{0}^{\infty} X^{\nu}\left\langle h_{x}^{-1}(n)\right\rangle W_{x} \mathrm{~d} x
$$

The values of $\left\langle h_{x}{ }^{-1}(n)\right\rangle$ calculated by eq 24 are summarized in the fourth column of Tables II and III. There are also shown in the fifth column the values of $h^{-1}\left(n_{x}\right)$ which are obtained with the aid of eq 6 and 21 . These two values, $\left\langle h_{x}{ }^{-1}(n)\right\rangle$, and $h^{-1}\left(n_{x}\right)$ are practically in agreement with each other, as was the case for $g(n)$. Thus we can safely put $\left\langle h_{x}{ }^{-1}(n)\right\rangle \simeq h^{-1}\left(n_{x}\right)$ in the calculation of eq 26. In these tables one finds that $h^{-1}\left(n_{x}\right)$ tends to 1.083 , instead of 1.0 , in the limit of $n_{x}=0$. This is, of course, due to the use of eq 21 in the range of small $n$ where this equation is invalid. However, the error involved in eq 21 is as small as about $2 \%$ when $n=1$ and about $1 \%$ when $n=5$. Thus the error involved in $S(\gamma, \nu)$ is neglibible for the region in which we are interested.

Results for $\nu=0.50,0.45$, and 0.40 are given in Table IV in the form of eq 25. It is interesting to note that the weight-average sedimentation constant of the polydisperse branched molecules having Stockmayer's molecular weight distribution is quite insensitive to the average branching and slightly smaller than that of the polydisperse
Table IV. Ratios of weight-average sedimentation constant of polydisperse branched and linear molecules having equal weight-average molecular weight as function of $\gamma$ and $\nu$

\begin{tabular}{lccc}
\hline \multicolumn{1}{c}{$\gamma$} & \multicolumn{3}{c}{$\left\langle S_{\mathrm{b}}\right\rangle\left\langle\left\langle S_{1}\right\rangle\right.$} \\
\cline { 2 - 4 } & $\nu=0.50$ & $\nu=0.45$ & $\nu=0.40$ \\
\hline 0 & 1.000 & 1.000 & 1.000 \\
0.10 & 0.985 & 0.985 & 0.985 \\
0.20 & 0.976 & 0.976 & 0.976 \\
0.30 & 0.968 & 0.968 & 0.968 \\
0.40 & 0.962 & 0.961 & 0.961 \\
0.50 & 0.956 & 0.954 & 0.954 \\
0.60 & 0.951 & 0.948 & 0.949 \\
0.70 & 0.946 & 0.940 & 0.938 \\
0.80 & 0.942 & 0.931 & 0.926 \\
0.90 & 0.940 & 0.919 & 0.906 \\
0.92 & 0.943 & 0.917 & 0.900 \\
0.94 & 0.951 & 0.916 & 0.894 \\
0.96 & 1.010 & 0.954 & 0.916 \\
\hline
\end{tabular}

linear molecules with the same weight-average molecular weight. These results could not be predicted from the theory of Kurata and Fukatsu for a monodisperse branched molecule, and show that for a polydisperse sample the molecular weight distribution has a remarkable effect on the average value of the sedimentation constant.

\section{EXPERIMENTAL}

\section{Samples}

Two series of randomly branched polymers, series $\mathrm{A}$ and $\mathrm{B}$, were polymerized in ampoules at $60^{\circ} \mathrm{C}$ for $5 \mathrm{hr}$. The polymerization conditions and conversion are given in Table V. As the conversion was kept constant within each series, the weight-average degree of polymerization of the primary molecules would be equal in the series $\mathrm{A}$ and $\mathrm{B}$ resrectively, i.e., it is equal to the weight-average degree of polymerization of A- 0 for series $\mathrm{A}$ and that of $\mathrm{B}-0$ for series $\mathrm{B}$. No gelation was detected under these polymerization condition. These polymers were purified by the precipitation method and put to use without further fractionation. In addition to these samples two fractionated samples having high moleculer weight, which were obtained by fractionating B-0, were also used as reference 
Table V. Polymerization conditions of samples

\begin{tabular}{cccccc}
\hline Sample no. & MMA, m $l$ & EDMA, $l$ & Benzene, $\mathrm{m} l$ & AIBN, $g$ & Conversion, \% \\
\hline A-0 & 20 & 0 & 50 & 0.1 & 39.8 \\
A-1 & 20 & 0.03 & 50 & 0.1 & 40.4 \\
A-2 & 20 & 0.05 & 50 & 0.1 & 40.6 \\
A-3 & 20 & 0.07 & 50 & 0.1 & 40.5 \\
A-4 & 20 & 0.10 & 50 & 0.1 & 40.8 \\
B-0 & 120 & 0 & 90 & 0.3 & 51.0 \\
B-1 & 120 & 0.03 & 90 & 0.3 & 51.9 \\
B-2 & 120 & 0.05 & 90 & 0.3 & 51.5 \\
B-3 & 120 & 0.07 & 90 & 0.3 & 51.0 \\
\hline
\end{tabular}

linear molecules.

All solvents used in measurements were purified from a special grade reagent by distillation.

\section{Light-Scattering Measurements}

Light-scattering measurements on all samples were made in methylethylketone (MEK) at $40^{\circ} \mathrm{C}$ using a Brice-type photoelectric photometer (manufactured by the Shimadzu Seisaku-Sho Company). Vertically polarized light of wavelength $436 \mathrm{~m} \mu$ was used as the incident beam and the vertical component of the scattered light was measured at each $10^{\circ}$ interval from $30^{\circ}$ to $140^{\circ}$.

Optical purification of the polymer solution was made by centrifugation or filtration through a cellafilter membrane. Calibration of the photometer was made to benzene. The refractiveindex increments of sample A-0 and A-4 were measured using a Debye-type differential refractometer (Shimadzu Seisaku-Sho Company) and was $0.122(\mathrm{ml} / \mathrm{g})$ in $\mathrm{MEK}$ at $40^{\circ} \mathrm{C}$ for both samples. We therefore used this value for all samples. From the Zimm plot, the weightaverage molecular weight, $Z$-average radius of gyration and second virial coefficient were obtained. In the Zimm plot, the angular dependence of the reciprocal scattered-light intensity is slightly concave downward for the samples B-2, B-3, and A-5, and is particularly noticeable in the last sample, as shown in Figure 1. For

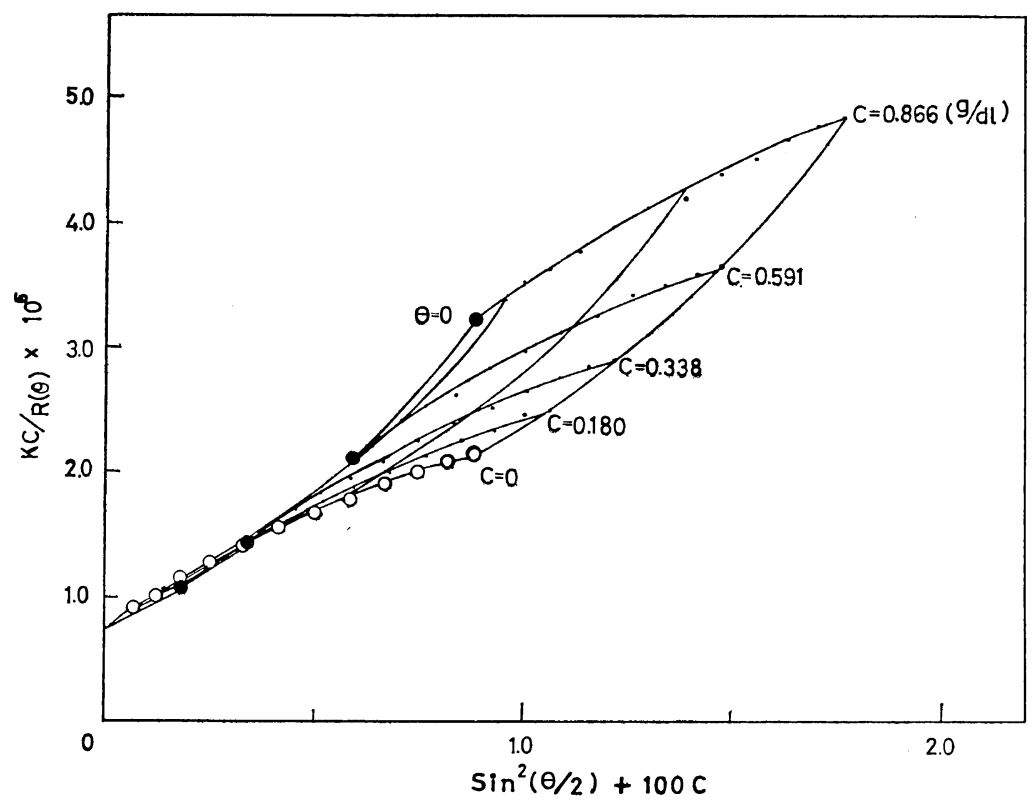

Figure 1. Zimm plot of sample A-4 in MEK at $40^{\circ} \mathrm{C}$. 
other samples, linear Zimm plots are obtained. Osmotic Pressure Measurements

In order to obtain the number-average molecular weight, osmotic-pressure measurements were made in benzene at $37^{\circ} \mathrm{C}$ using a high-speed membrane osmometer (Hewlett Packard Co.). Gel cellophane was used as a semipermeable membrane.

\section{Sedimentation}

Sedimentation velocity was measured in ethyl acetate (EtAc) at $20^{\circ} \mathrm{C}$ using a Hitachi UCA-1 type ultracentrifuge. Measurements were carried out on five solutions of initial concentration between 0.2 and $0.6(\mathrm{~g} / \mathrm{d} l)$ at rotor speed 40370 r.p.m., and Schlieren diagrams were obtained at varying intervals.

\section{Viscosity}

A dilution viscometer of the Ubbelohde type was used. Measurements were carried out in three solvents, i.e., in $\mathrm{MEK}$ at $25^{\circ} \mathrm{C}$; in EtAc at $20^{\circ} \mathrm{C}$ and in acetonitrile $\left(\mathrm{CH}_{3} \mathrm{CN}\right)$ at $45^{\circ} \mathrm{C}$. Correction for kinetic energy was ignored in all measurements.

\section{RESULTS AND DISCUSSION}

The results of light-scattering and osmoticpressure measurements are summarized in Table VI. In the sixth column of this table are given indexes of polydispersity, $M_{w} / M_{n}$. As expected, the ratio increases with greater branching in the sample. The anomalous angular dependence of the reciprocal scattered-light intensity in the Zimm plot for sample A-5 is due to the broad molecular weight distribution.
Figure 2 shows the double logarithmic plot of the radius of gyration against the weight-average molecular weight, $M_{w}$. These points fall in an almost straight line regardless of chain branching. This implies that the $Z$-average mean square radius of gyration of polydisperse branched molecules is equal to that of linear ones with the same $M_{w}$. When the molecular weight distribution is of the Stockmayer type, this type of behavior can be proved theoretically. ${ }^{4,6}$ In such a case details of branching cannot be obtained from the $Z$-average mean square radius of gyration of polydisperse samples.

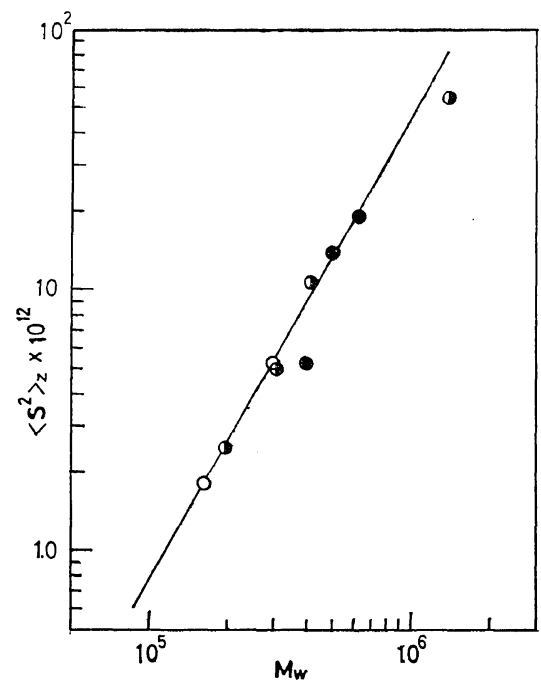

Figure 2. $\log -\log$ plot of mean square radius of gyration against $\boldsymbol{M}_{w}$ : $\bigcirc$, linear molecule; $\boldsymbol{O}$, branched molecule, series A; $\bullet$, branched molecule, series B.

Table VI. Results of light-scattering and osmotic-pressure measurements

\begin{tabular}{cccccc}
\hline Sample no. & $M_{w} \times 10^{-4}$ & $A_{2} \times 10^{4}\left[\mathrm{~mol} / \mathrm{cc} \mathrm{g}^{2}\right]$ & $\left\langle S^{2}\right\rangle_{2^{1 / 2}}, \AA$ & $M_{n} \times 10^{-4}$ & $M_{w} / M_{n}$ \\
\hline A-0 & 16.2 & 3.44 & 135 & 10.5 & 1.54 \\
A-1 & 19.5 & 2.51 & 159 & 10.9 & 1.79 \\
A-2 & 30.1 & 2.26 & 225 & 14.2 & 2.12 \\
A-3 & 40.8 & 1.84 & 328 & 13.6 & 3.00 \\
A-4 & 134.0 & 1.28 & 749 & 13.2 & 10.1 \\
B-0 & 29.6 & 2.60 & 230 & 20.9 & 1.41 \\
B-1 & 39.6 & 2.78 & 229 & 23.5 & 1.69 \\
B-2 & 47.7 & 2.20 & 377 & 27.5 & 1.73 \\
B-3 & 62.0 & 2.20 & 440 & 24.1 & 2.57 \\
F-7 & 58.5 & 2.72 & 279 & 55.5 & 1.05 \\
F-8 & 94.0 & 2.34 & 423 & 74.5 & 1.26 \\
\hline
\end{tabular}


In our samples, the weight-average molecular weight of primary molecules of the two series

Table VII. Branching parameter, $\gamma$ and weightaverage number of branch unit, $n_{w}$, of samples

\begin{tabular}{ccc}
\hline Sample no. & $\gamma$ & $n_{w}[=\gamma /(1-\gamma)]$ \\
\hline A-1 & 0.170 & 0.205 \\
A-2 & 0.461 & 0.856 \\
A-3 & 0.603 & 1.52 \\
A-4 & 0.879 & 7.25 \\
B-1 & 0.253 & 0.338 \\
B-2 & 0.380 & 0.613 \\
B-3 & 0.523 & 1.094 \\
\hline
\end{tabular}

$A$ and $B$ are respectively equal to that of $A-0$ and B-0. Accordingly we can evaluate the branching parameter $\gamma$ from eq 7 , and hence $n_{w}$ from eq 9. These values are given in Table VII.

The results of intrinsic-viscocity measurements in various solvents are shown in Table VIII. These intrinsic viscosities are plotted in double logarithm against $M_{w}$ in Figure 3-5.

In these figures, there are four plots (open circles) for the linear molecles, where two of them are for the polydisperese molecules (A-0 and $\mathrm{B}-0)$ and the others are for the fractionated samples (F-7 and F-8). The $[\eta]$ vs. $M_{w}$ relation

Table VIII. Results of intrinsic viscosities in various solvents

\begin{tabular}{|c|c|c|c|c|c|c|}
\hline \multirow{2}{*}{$\begin{array}{c}\text { Sample } \\
\text { no. }\end{array}$} & \multicolumn{2}{|c|}{$\mathrm{MEK}, 25^{\circ} \mathrm{C}$} & \multicolumn{2}{|c|}{ EtAc, $20^{\circ} \mathrm{C}$} & \multicolumn{2}{|c|}{$\mathrm{CH}_{3} \mathrm{CN}, 45^{\circ} \mathrm{C}$} \\
\hline & {$[\eta], \mathrm{d} l / \mathrm{g}$} & $k^{\prime}$ & {$[\eta]$} & $k^{\prime}$ & {$[\eta]$} & $k^{\prime}$ \\
\hline $\mathrm{A}-0$ & 0.360 & 0.555 & 0.329 & 0.550 & 0.194 & 1.04 \\
\hline A-1 & 0.402 & 0.550 & 0.353 & 0.670 & 0.212 & 0.962 \\
\hline A-2 & 0.458 & 0.557 & 0.377 & 0.645 & 0.218 & 1.00 \\
\hline$A-3$ & 0.475 & 0.531 & 0.451 & 0.550 & 0.240 & 1.06 \\
\hline A-4 & 0.632 & 0.512 & 0.574 & 0.546 & 0.290 & 0.994 \\
\hline B-0 & 0.571 & 0.465 & 0.502 & 0.527 & 0.274 & 0.970 \\
\hline B-1 & 0.585 & 0.465 & 0.532 & 0.545 & 0.279 & 1.02 \\
\hline B-2 & 0.649 & 0.498 & 0.586 & 0.505 & 0.301 & 0.990 \\
\hline B-3 & 0.698 & 0.486 & 0.617 & 0.480 & 0.306 & 1.01 \\
\hline F-7 & 0.877 & 0.510 & 0.744 & 0.595 & 0.406 & 0.950 \\
\hline F-8 & 1.191 & 0.456 & 1.027 & 0.540 & 0.504 & 0.920 \\
\hline
\end{tabular}

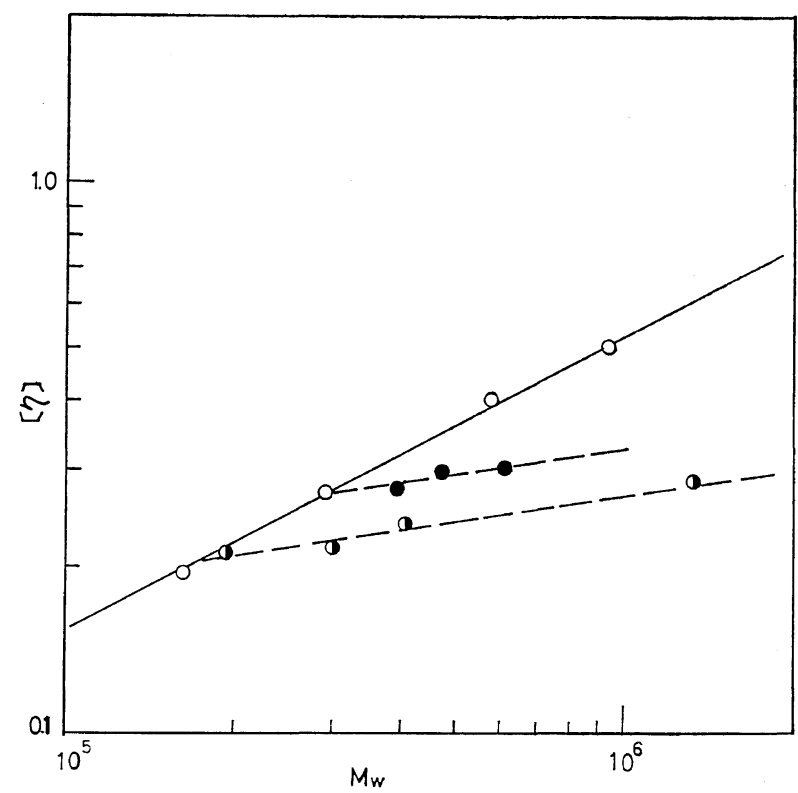

Figure 3. Log-log plot of intrinsic viscosity against $M_{w}$ in acetonitrile at $45^{\circ} \mathrm{C}$. Symbols are the same as in Figure 2 
Dilute Solution Properties of Branched PMMA. I

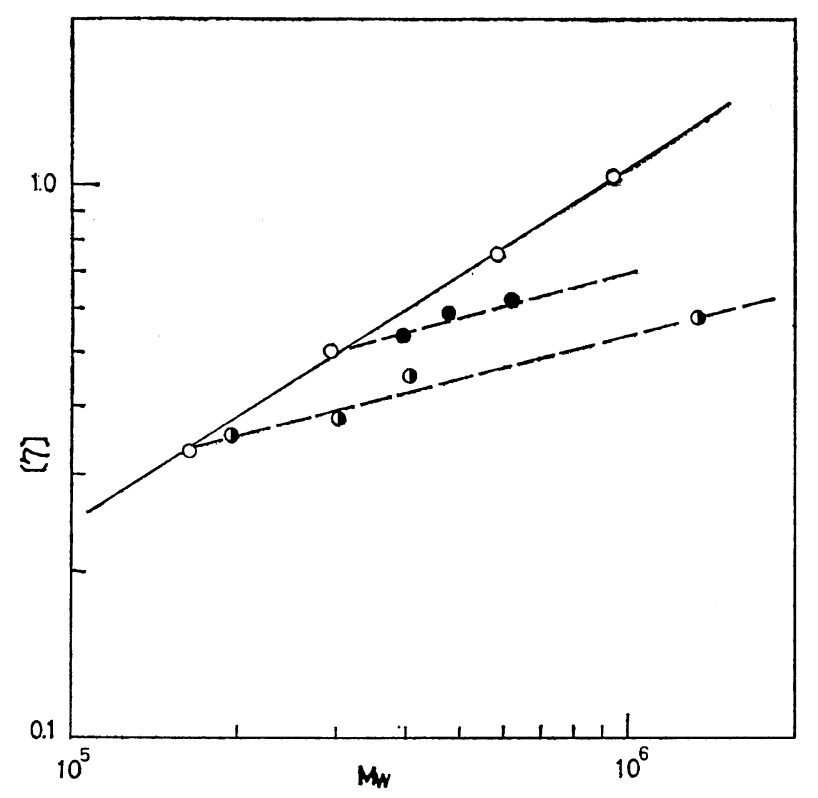

Figure 4. $\log -\log$ plot of intrinsic-viosocity against $M_{w}$ in ethyl acetate at $20^{\circ} \mathrm{C}$. Symbols are the same as in Figure 2.

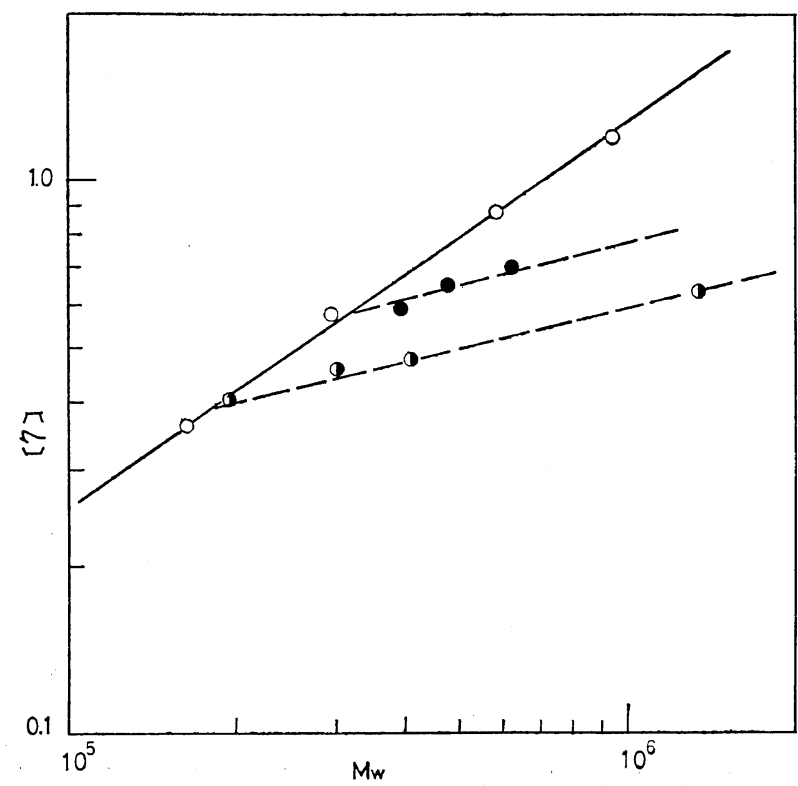

Figure 5. Log-log plot of intrinsic viscosity against $M_{w}$ in MEK at $40^{\circ} \mathrm{C}$. Symbols are the same as in Figure 2.

is not particularly dependent on the molecular weight distribution of the sample and we can obtain the intrinsic viscosity and molecular weight relation for the polydisperse linear molecules from the straight line shown in the figures as follows: 
$[\eta]_{1}=3.31 \times 10^{-4} M_{w}^{0.532} \quad\left(\right.$ in $\mathrm{CH}_{3} \mathrm{CN}$ at $\left.45^{\circ} \mathrm{C}\right)$

$[\eta]_{1}=15.4 \times 10^{-5} M_{w}^{0.641} \quad\left(\right.$ in EtAc at $20^{\circ} \mathrm{C}$ )

$$
[\eta]_{1}=8.71 \times 10^{-5} M_{w}^{0.695} \text { (in MEK at } 25^{\circ} \mathrm{C} \text { ) }
$$

T. G. Fox ${ }^{11}$ reported that the theta temperature for PMMA was $45^{\circ} \mathrm{C}$ in acetonitrile, but our results shows the theta temperature is slightly lower than $45^{\circ} \mathrm{C}$.

As shown in Table $I$, the value of $\left\langle[\eta]_{b}\right\rangle \mid$ $\left\langle[\eta]_{1}\right\rangle$ is not greatly dependent on the exponent $a$ of $M_{w}$ in the viscosity equation. The intrinsic viscosity ratios in three different solvents, i.e., acetonitrile, ethyl acetate, and methylethylketone, can be compared with the theoretical values for $a=0.50,0.60$, and 0.70 , respectively. In order to make this comparison, experimental values of $\left\langle[\eta]_{b}\right\rangle\left\langle[\eta]_{1}\right\rangle$ were obtained with the aid of the intrinsic viscosity equations $27-29$ and plotted against $\gamma$ in Figures 6-8, respectively. In these figures, solid, dashed, and broken lines show the theoretical curves for $g^{1 / 2}, g$, and $g^{3 / 2}$, respec- tively. From these figures, it is clear that near theta temperatures or in poor solvent the viscosity equation of Zimm and Kilb is in close agreement with the experiment, but in good solvents (data in MEK), experimental points deviate slightly downward from the $g^{1 / 2}$ curve in the region of large $\gamma$ values. The reason for this deviation is not yet clear, but may be due to the excluded volume effect; for the theory of Zimm and Kilb is only valid at theta temperatures. Thus it is concluded that the $g^{1 / 2}$ rule is valid for randomly branched molecules in theta and poor solvents, but is invalid in good solvents for the sample with much branching. In such a case a slightly larger value, instead of $1 / 2$, may be used for the exponent of $g$.

Zimm and Stockmayer calculated the weightaverage $g$ value, $\langle g\rangle_{w}$, for polydisperse randomly branched molecules with the aid of the Stockmayer distribution function. In the case of tetrafunctionality it is given simply as

$$
\left\langle g_{4}\right\rangle_{w}=\left(\frac{1}{n_{w}}\right) \ln \left(1+n_{w}\right)
$$

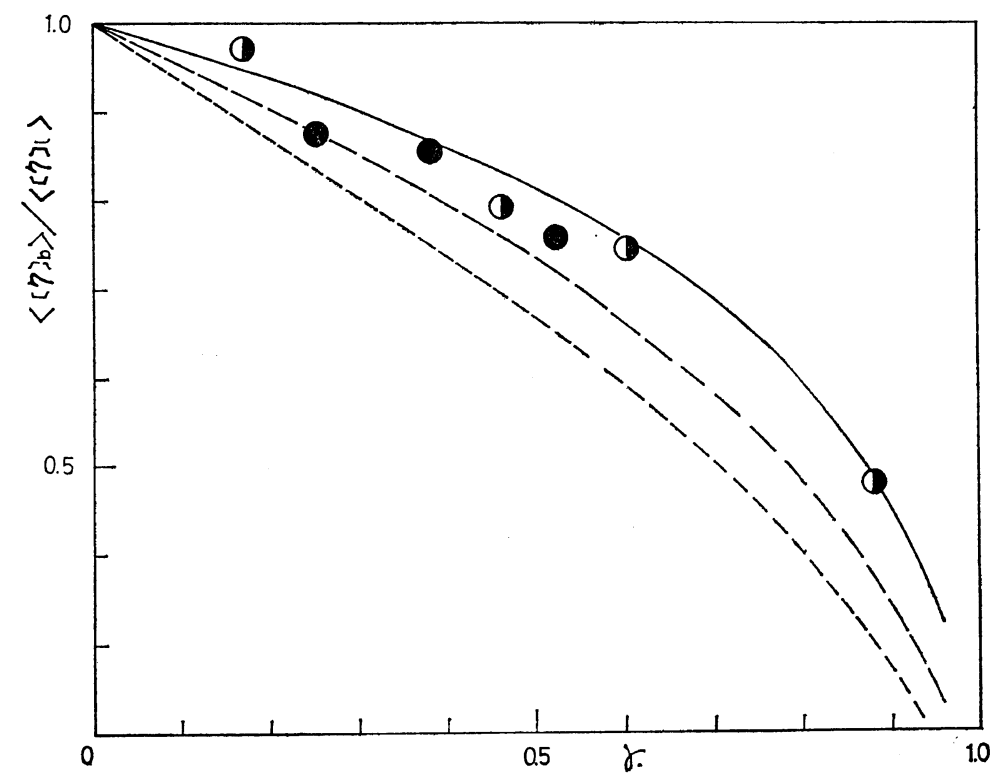

Figure 6. Ratios of intrinsic viscosities of polydisperse branched and linear molecules, having equal weight-average molecular weight, as a function of the branching parameter $\gamma$. Circles are experimental points measured in acetonitrile at $45^{\circ} \mathrm{C}$ and the symbols are the same as in Fgure 2.

Curved lines are the theoretical with $a=0.50$ : solid curve, $B(g)=g^{1 / 2}$; dashed curve, $B(g)=g$; broken curve, $B(g)=g^{3 / 2}$. 
Dilute Solution Properties of Branched PMMA. I

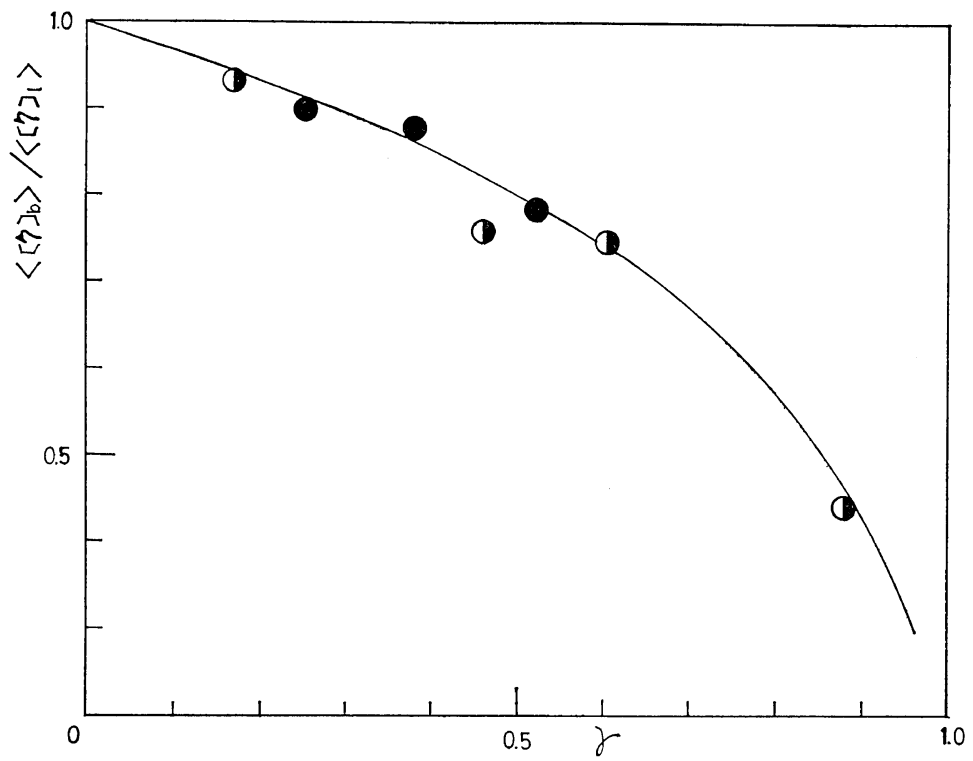

Figure 7. Ratios of intrinsic viscosities of polydisperse branched and linear molecules, having equal weight-average molecular weight, as a function of the branching parameter $\gamma$. Circles are experimental points measured in ethyl acetate at $20^{\circ} \mathrm{C}$ and the symbols are the same as in Figure 2. Solid curve is the theoretical with $a=0.60$ and $B(g)=g^{1 / 2}$.

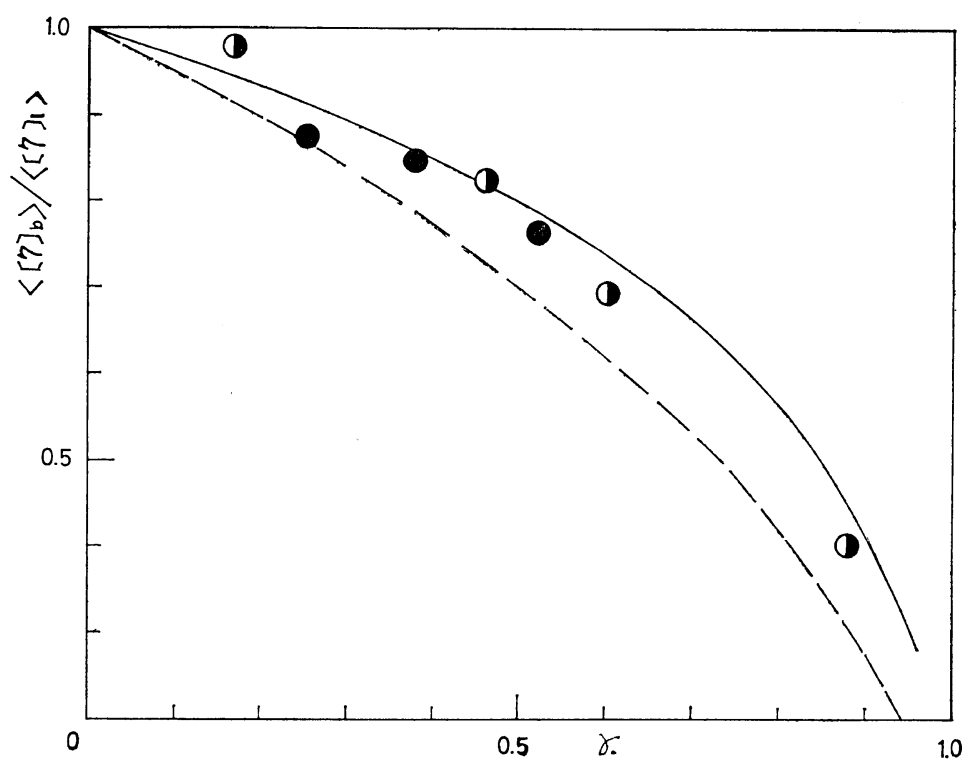

Figure 8. Ratios of intrinsic viscosities of polydisperse branched and linear molecules having equal weight-average molecular weight, as a function of the branching parameter $\gamma$. Circles are experimental points measured in MEK at $40^{\circ} \mathrm{C}$ and symbols are as for Figure 2. Curved lines are the theoretical with $a=0.70$ : solid curve, $B(g)=g^{1 / 2}$; dashed curve, $B(g)=g$. 


\section{K. Kamada and H. SAto}

If we use eq 31

$$
\left\langle[\eta]_{\mathrm{b}}\right\rangle=\left\langle g_{4}\right\rangle_{w}{ }^{1 / 2}\left\langle[\eta]_{1}\right\rangle
$$

we could easily obtain the weight-average branch units, $\boldsymbol{n}_{w}$, of the sample from the intrinsic-viscosity ratio $\left\langle[\eta]_{\mathrm{b}}\right\rangle /\left\langle[\eta]_{1}\right\rangle$ with the aid of eq 30 and 31 . In the theta state, the $n_{w}$ obtained from eq 17 and 9 is compared with the $n_{w}{ }^{\prime}$ from eq 30 and 31 for various $\left\langle[\eta]_{\mathrm{b}}\right\rangle \mid$ $\left\langle[\eta]_{1}\right\rangle$ values in Figure 9. The slope of the straight line in Figure 9 is larger than $1 / 2$, that is, $n_{w}{ }^{\prime}$ is larger than the $n_{w}$ obtained from the intrinsic viscosity precisely taking into account the distribution of the molecular weight and the branch unit of the sample. The error involved in $\boldsymbol{n}_{w}{ }^{\prime}$ increases as the branching increases and it is about $20 \%$ for $n_{w}=1$ (for $\gamma=0.50$ ) and about $40 \%$ for $n_{w}=10$ (for $\gamma=0.90$ ). Thus, considering the error involved in the determination of molecular weight, for the sample having a relatively small number of average branch units, we can qualitatively evaluate the weightaverage number of branch units of a sample from the simple equations 30 and 31 .

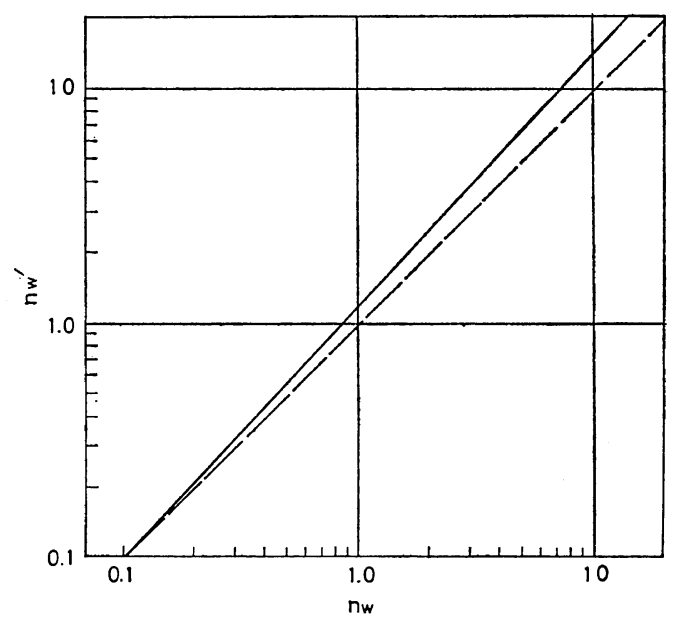

Figure 9. Relation between weight-average number of branch unit of polydisperse branched molecules $n_{w}$, obtained by eq 17 and 9 , and $n_{w}{ }^{\prime}$ derived by simple eq 30 and 31 .

The results of sedimentation measurements are given in Table IX. $S_{\mathrm{o}} \mathrm{m}$ is an apparent sedimentation constant which was obtained by following the movement of the peak position in Schlieren diagrams and the usual extrapolation to zero concentration. $k_{s}$ is the parameter of concentration dependence which was obtained from the slope in $1 / S_{\mathrm{c}}{ }^{\mathrm{m}} v \boldsymbol{v}$. concentration plots, where $S_{\mathrm{c}} \mathrm{m}$ is the apparent sedimentation constant at a given concentration. It is found in Table IX that the value of $S_{0}$ m is almost constant in each series independent of the molecular weight and branching, but rather decreases with decreasing the molecular weight. As mentioned previously, $S_{\mathrm{o}}{ }^{\mathrm{m}}$ was obtained from the peak in the Schlieren diagram; it does not represent a true average sedimentation constant in such polydisperse systems. The peak position corresponds rather to the maximum position of the molecular weight distribution curve for the sample. In Tables II and III one finds the maximum position of $W_{x}$ is near $X=0.875$ and 0.750 for $\gamma=0.50$ and 0.90 respectively, and that is also near $X=1.0$ for $\gamma=0$. That is, as $\gamma$ increases, the peak position of the molecular weight distribution curve moves slightly in the direction of lower molecular weight. The slight change in $S_{\mathrm{o}}{ }^{\mathrm{m}}$, in spite of the large variation of $M_{w}$, in Table IX is considered to represent these phenomena.

Table IX. Results of sedimentation-velocity measurements

\begin{tabular}{ccc}
\hline Sample no. & $S_{\mathrm{o}} \mathrm{m}(\boldsymbol{S})$ & $k_{\mathrm{s}}$ \\
\hline A-0 & 10.1 & 0.570 \\
A-1 & 10.1 & 0.451 \\
A-2 & 10.5 & 0.516 \\
A-3 & 9.81 & 0.348 \\
A-4 & 9.92 & 0.296 \\
B-0 & 13.4 & 0.913 \\
B-1 & 13.7 & 0.910 \\
B-2 & 13.6 & 0.840 \\
B-3 & 13.6 & 0.819 \\
\hline
\end{tabular}

To make a comparison with the theoretical value in Table IV, we tried laborious calculations to obtain the weight-average sedimentation constant $\langle S\rangle$ with the usual methods but owing to the broad molecular weight distribution of the samples irregularities occurred at the stage of diffusion correction and it was impossible to obtain this average value. Thus it is concluded that for polydisperse branched molecules it is impossible to evaluate the chain branching from 
the sedimentation constant and if we wish to learn more about it, we must use samples as monodisperse as possible.

Acknowledgement. We wish to thank Professor Michio Kurata, of the Institute for Chemical Research, Kyoto University, for his many suggestions and comments throughout this series of studies. Thanks are also due to Mitsubishi Rayon Company, Ltd. for permission to publish this work; to Mr. Y. Kinoshita for providing the samples used and to Mr. H. Masumoto and Mr. S. Hakoda for their assistance in the experiments.

\section{REFERENCES}

1. M. Morton, T. E. Helminiak, S. D. Gadkary, and F. Bueche, J. Polym. Sci., 57, 471 (1962).
2. T. A. Orofino and F. Wenger, J. Phys. Chem., 67, 566 (1963).

3. B. H. Zimm and R.W. Kilb, J. Polym. Sci., 37, 19 (1959).

4. R. W. Kilb, J. Polym. Sci., 38, 403 (1959).

5. W. H. Stockmayer, J. Chem. Phys., 11, 45 (1943).

6. W. H. Stockmayer, J. Chem. Phys., 12, 125 (1944).

7. B. H. Zimm and W. H. Stockmayer, J. Chem. Phys., 17, 1301 (1949).

8. W. H. Stockmayer and M. Fixman, Ann. N. Y. Acad. Sci., 57, 334 (1953).

9. E.S. Pearson, "Tables of the Incomplete Gamma Function," Biometrika, Cambridge Univ. Press, 1946.

10. M. Kurata and M. Fukatsu, J. Chem. Phys., 41, 2934 (1964).

11. T. G. Fox, Polymer, 3, 111 (1962). 